\title{
Targeted kinetic strategy for improving the thermal conductivity of epoxy composite containing percolating multi-layer graphene oxide chains
}

\author{
T. Zhou ${ }^{*}$, H. Koga ${ }^{2}$, M. Nogi ${ }^{2}$, T. Sugahara ${ }^{2}$, S. Nagao ${ }^{2}$, T. T. Nge ${ }^{2}$, K. Suganuma ${ }^{2}$ H-W. Cui ${ }^{2}$, \\ F. Liu ${ }^{1}$, Y. Nishina ${ }^{3}$ \\ ${ }^{1}$ School of Materials Science and Engineering, Nanjing University of Science and Technology, 210094 Nanjing, China \\ ${ }^{2}$ The Institute of Scientific and Industrial Research, Osaka University, Mihogaoka 8-1, Ibaraki, 567-0047 Osaka, Japan \\ ${ }^{3}$ Research Core for Interdisciplinary Science, Okayama University, Tsushimanaka, Kita-ku, 700-8530 Okayama, Japan
}

\begin{abstract}
By adding $2 \mathrm{wt} \%$ multi-layer graphene oxide (MGO) to an epoxy resin, the thermal conductivity of the composite reached a maximum, 2.03 times that of the epoxy. The presence of $2 \mathrm{wt} \% \mathrm{MGO}$ percolating chains leads to an unprecedentedly sharp rise in energy barrier at final curing stage, but an increased epoxy curing degree $\left(\alpha_{\mathrm{IR}}\right)$ is observed; however, this $\alpha_{\text {IR }}$ difference nearly disappears after aging or thermal annealing. These results suggest that the steep concentration gradient of $-\mathrm{OH}$, originated from the $2 \mathrm{wt} \% \mathrm{MGO}$ percolating chains, exerts the vital driving force on the residual isolated/ trapped epoxy to conquer barrier for epoxy-MGO reaction. A modified Shrinking Core Model customized for the special layered-structure of MGO sheet was proposed to understand the resistance variation during the intercalative epoxy-MGO reaction. It shows that the promoted intercalative crosslinking is highly desirable for further improving the thermal conductivity of the composite, but it meets with increased resistance. Guided by the kinetic studies, targeted optimization on the cure processing strategy was accordingly proposed to promote the intercalative crosslinking, a thermal conductivity, 2.96 times that of the epoxy, was got with only a small amount $\left(30^{\circ} \mathrm{C}\right)$ increase of the post-heating temperature.
\end{abstract}

Keywords: polymer composites, nanocomposites, thermal properties, graphene oxide

\section{Introduction}

The thermal conductivity of materials are becoming increasingly important in tandem with the need for more efficient heat removal in numerous advanced systems such as printed electronics [1], automotive and aerospace products [2]. Due to the fascinating and especially, technologically useful properties, worldwide, an enormous amount of research effort goes into the utilization of graphene materials (GMs), particularly in strengthening polymers. Strategies involving GM content, exfoliation and dispersion state of GM, GM/polymer interfacial interaction, etc. have been taken into account; however, the property improvements are still far from expectations and the thermal conductivity in particular [3-5]. The polymerization of monomers into the polymer matrix is of vital importance to the final properties of composites, several kinetic works reported the effect of GMs on the polymerization [6-11], specifically, Wu et al. [6] found a vulcanization stage dependence of activation energy $(E)$ variation of graphene/natural rubber system with Ozawa and Kissinger methods; Wang and Qiu [7] noticed an accelerated isothermal melt crystallization of poly (1-lactic acid) by graphene oxide (GO) with isoconversional method; Jing and Qiu [8] used Avrami

\footnotetext{
*Corresponding author, e-mail: ztltianle999@hotmail.com (C) BME-PT
} 
equation and revealed that the isothermal melt crystallization rate of poly(3-hydroxybutyrate) depends on the GO loading and the crystallization temperature; Zhang et al. [9] used Kissinger equation and noticed that GO decreases the $E$ of nylon 6; Qiu et al. [10] used isoconversional method and found that the effect of GO on the $E$ of a tetrafunctional tetraglycidyl-4,4'-diaminodiphenylmethane cured with 4,4'-diaminodiphenylsulfone depends on GO content and curing stage; and with Kamal and Ryan's model as well as Isayev and Deng's model, Allahbakhsh et al. [11] revealed that $E$ of GO/ethylene-propylene-diene rubber system depends on the GO content and the dispersion quality of GO. Notably, hardly any kinetic works directly contribute to the performance improvement of GM/polymer composites, worse still, the polymerizing strategy for the polymer matrices are extensively misused for the GM/polymer composites.

MGO based composites can be produced via in-situ intercalative polymerization [12]. Successful polymerizations of epoxy, polyaniline, polypyrrole, acrylic, poly(vinyl alcohol), poly(methyl methacrylate) and poly(arylene disulfide) with MGO have been reported [13-18]. However, most of these studies did not pay attention to the resistance variation of the progressive intercalation process.

In this study, the effect of multi-layer GO (MGO) percolating chains on the curing kinetics of diglycidyl ether of bisphenol-A (DGEBA)/2-ethyl-4-methylimidazole (EMI-2,4) system (a widely used epoxy system in industries) was studied. Formation mechanism of the MGO/epoxy percolating network was explored, for the first time based on the real-time $E$ variation. A modified Shrinking Core Model customized for the special layered-structure of MGO sheet was proposed to understand the resistance variation during the intercalative epoxy-MGO reaction. The main aim is to effectively improve the thermal conductivity of epoxy composite containing percolating MGO chains by targeted kinetic strategy.

\section{Experimental}

\subsection{Materials}

So far, GO has been extensively utilized in polymer composites. Besides the lower cost and higher yield production than graphene, GO is heavily oxygenated (its basal plane carbon atoms are decorated with $-\mathrm{OH}$ and $\mathrm{C}-\mathrm{O}-\mathrm{C}$ groups, while $-\mathrm{OH}$ and $-\mathrm{COOH}$ groups at the edge), not only enabling an improved
$\mathrm{GO} /$ polymer interfacial interaction and better dispersion state of GO in matrix, but also reducing the interplanar forces and increasing the inter-layer spacing, beneficial to in-situ intercalative polymerization [3-5]. Furthermore, monolayer or few-layer GO not necessarily gives the best reinforcement since too much amount of wrinkling of GO weakens its effectiveness for forming conductive network, therefore, MGO is more desirable in this work. $\mathrm{MGO} /$ water mixture (Rap GO TQ2, low oxidation grade) was supplied by NiSiNa materials Co., Ltd, Japan. Before being used, MGO/water mixture was moderately centrifugated (10000 rpm, $10 \mathrm{~min})$ with abundant ethanol for 3 times to replace water solvent with ethanol solvent as well as removing any agglomerated MGO.

Epoxy resin employed was a nominally difunctional epoxy resin, i.e. Epon 828 (DGEBA with epoxy value of $0.48-0.52 \mathrm{~mol} / 100 \mathrm{~g}$, supplied by Shanghai Resin Co. Ltd., China). Curing agent EMI-2,4 was supplied by Wako Pure Chemical Industries, Ltd., Japan. The employed ratio of DGEBA and EMI-2,4 was 100:6. Graphite particles (sized at $500 \mu \mathrm{m}$, carbon content $>99 \%$ ) were supplied by Xinfangyuan Co. Ltd., China. Other agents were analytically pure grade and supplied by Wako Pure Chemical Industries, Ltd., Japan.

\subsection{Preparation of MGO/DGEBA/EMI-2,4 mixture}

$\mathrm{MGO} /$ ethanol mixture was sonicated for $1.5 \mathrm{~h}$ in advance to break down agglomerates. A certain amount of MGO/ethanol mixture was mixed with epoxy precursor (DGEBA) and EMI-2,4, then the mixture was stirred with a rotation speed of $2000 \mathrm{rpm}$ as well as a simultaneous revolution speed of $2000 \mathrm{rpm}$ for 6 times (each time for $5 \mathrm{~min}$ ) by using Thinky Mixer (ARV310, Thinky Co. Japan), a vacuum pressure reduction function of which removed solvents and submicron air bubbles as well as giving an outstanding dispersion performance (This step is unique in comparison with other methods for nanocarbon-based composite preparation, not only because most of solvent can be removed during the mixing process, but also because excellent dispersion of nanocarbon fillers is guaranteed as the solvent reduces). Each time after mixing for $5 \mathrm{~min}$, an ice bath was utilized to keep the temperature of mixture around $283 \mathrm{~K}$ (low-temperature treatment produces better nanofiller dispersion state than high- 
temperature treatment [19] as well as preventing from an untimely occurrence of curing), then the mixture was weighted to determine the precise amount of MGO introduced into matrix and the amount of $\mathrm{MGO} /$ water mixture needed to add. Repeating this process until the MGO content was $0.5,1,2,2.2,2.5$ or $3 \%$ by weight of epoxy resin.

\subsection{Preparation of MGO/epoxy composite}

MGO/epoxy composite was prepared by in-situ polymerization. Although Thinky Mixer uses sophisticated approaches in removing solvents during mixing and thus reducing the defects of voids and pores in the final composite, it is necessary to degass the mixture after the casting step to remove the air absorbed during this step. Basic preparation process involved (a) casting the mixture in mould, (b) repeatedly degassing the mixture in vacuum drying oven at $313 \mathrm{~K}$ until no air bubble appears on the surface of the mixture, (c) curing the mixture at $313 \mathrm{~K}$ for $1 \mathrm{~h}$, $378 \mathrm{~K}$ for $1.5 \mathrm{~h}$, and $458 \mathrm{~K}$ for $1.5 \mathrm{~h}$ (improved cure processing strategies were listed in the Results and discussion part), and (d) cooling to room temperature, then demoulding.

\subsection{Characterization}

Morphological studies were carried out using transmission electron microscopy (TEM, JEM-3000F, JEOL Japan Co., Ltd.) and field emission scanning electron microscopy (FE-SEM, JSM-6700F, JEOL Japan Co., Ltd.). Specimens were coated with a thin platinum layer before FE-SEM observation.

Infrared spectra were tested using a FTIR spectrometer (Perkin-Elmer frontier, Perkin-Elmer Japan Co., Ltd.) for evaluating the functional groups of MGO as well as the epoxy curing degree $\left(\alpha_{\mathrm{IR}}\right)$ of cured samples. FTIR spectra were obtained by an accumulation of 16 scans in a range of frequency from 4000 to $700 \mathrm{~cm}^{-1}$ with a resolution of $4 \mathrm{~cm}^{-1}$. Attenuated total reflectance spectra were collected from the polymeric films. A set of three specimens was tested for each material after pre-dried in air at $373 \mathrm{~K}$ for $12 \mathrm{~h}$.

Wide-angle X-ray diffractometry (WXRD) (Rigaku RINT RAPID II, $40 \mathrm{kV}, 20 \mathrm{~mA}$ ) with CuKa radiation (X-ray wavelength $k=0.154 \mathrm{~nm}$ ) was used to examine the crystal structure of the samples. The range of diffraction angles $(2 \theta)$ was $0 \sim 50^{\circ}$. A set of three specimens was tested for each material.
Approximately 4 mg MGO/DGEBA/EMI-2,4 mixture was weighed accurately into an aluminum differential scanning calorimetry (DSC) sample pan and then covered with an aluminum lid. DSC measurements were carried out by using a NETZSCH DSC 204 F1 system (NETZSCH Instruments Japan Co., Ltd.). The DSC was calibrated with high purity indium; $\mathrm{a}-\mathrm{Al}_{2} \mathrm{O}_{3}$ was used as the reference material. Dynamic experiments were carried out under an argon flow rate of $25 \mathrm{~mL} / \mathrm{min}$ and a temperature ranging from 313 to $623 \mathrm{~K}$ at different heating rates of $10,15,20,25 \mathrm{~K} / \mathrm{min}$. The reaction was considered to be complete when the rate curve leveled off to a baseline. The cured sample was left in the DSC cell and cooled to the room temperature. Then the cured samples were tested by FITR and $\alpha_{\text {IR }}$ was obtained by measuring the reactive absorbance of the epoxy band $\left(914 \mathrm{~cm}^{-1}\right)$ against the absorbance of the band associated with the benzene ring $\left(1610 \mathrm{~cm}^{-1}\right)$ which acts as a reference in spectra. These absorbances were calculated in the spectra processed by a baseline correction to obtain comparable results. To determine the glass transition temperature $\left(T_{\mathrm{g}}\right)$ of reacted product, the cured sample was scanned again by DSC to $623 \mathrm{~K}$ at $10 \mathrm{~K} / \mathrm{min}$. The intermediate point of the heat flow step of the second diagram was defined as DSC $T_{\mathrm{g}}$. A set of three specimens was tested for each material.

Thermal diffusivity $\left(\delta, \mathrm{mm}^{2} / \mathrm{s}\right)$ at room temperature was measured on square plate samples $(10 \times 10 \times$ $1 \mathrm{~mm}^{3}$ ) by laser flash method (nanoflash LFA 447 system, NETZSCH Instruments Japan Co., Ltd, a total of 5 shots were taken per sample set), specific heat $(C, \mathrm{~J} / \mathrm{gK})$ at room temperature was measured on disk samples (6 $\mathrm{mm}$ diameter, $1 \mathrm{~mm}$ thickness) by DSC (NETZSCH DSC 204 F1 system, NETZSCH Instruments Japan Co., Ltd.), and bulk density ( $\rho$, $\mathrm{g} / \mathrm{cm}^{3}$ ) of specimen was measured by water displacement. For each measurement, three samples were tested five times. After that, thermal conductivity $(\lambda$, $\mathrm{W} / \mathrm{mK}$ ) was calculated by Equation (1):

$\lambda=\delta \cdot C \cdot \rho$

Coefficient of thermal expansion (CTE) was tested on square plate samples $(25 \times 5 \times 1 \mathrm{~mm} 3)$ by SII TMA/ SS7100 (Hitachi High-Tech Science Co., Japan, tensile mode with a $5 \mathrm{mN}$ load) at a heating rate of $5 \mathrm{~K} / \mathrm{min}$ in $\mathrm{N}_{2}$ atmosphere. The CTE values were 
determined from the second run of 303 443 K profiles. A set of three specimens was tested for each material.

Thermal degradation behavior was characterized by TGA (TG-DTA200se/h/24/1 system, NETZSCH Instruments Japan Co., Ltd.) at a scan rate of $10 \mathrm{~K} / \mathrm{min}$ to $1023 \mathrm{~K}$ in $\mathrm{N}_{2}$. A set of three specimens was tested for each material. Specimens were predried in air at $373 \mathrm{~K}$ for $12 \mathrm{~h}$ to remove absorbed water.

\section{Results and discussion}

\subsection{Morphology and characterization of MGO}

Morphology and characterization of MGO greatly determine its contribution to the performance improvement of composites. Typical TEM image of a MGO sheet (Figure 1a) exhibits a crumpled paperlike morphology, core section of the sheet (see the

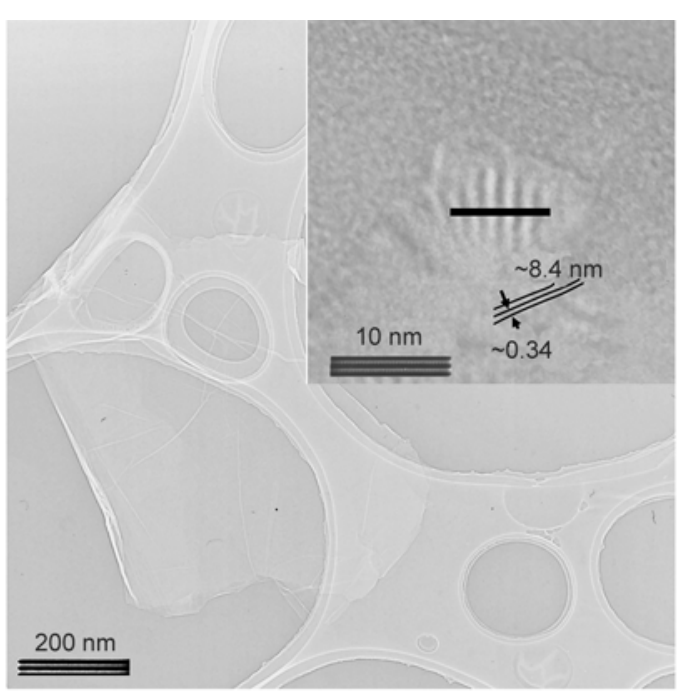

a)

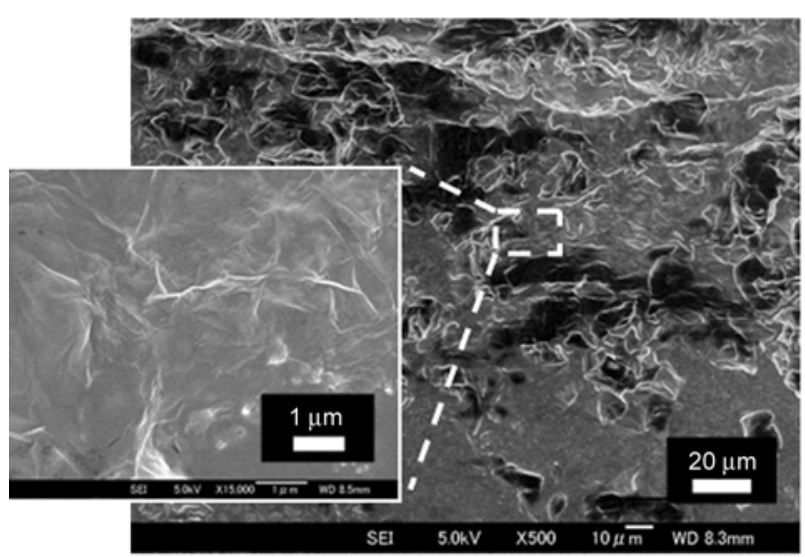

c) inset in Figure 1a) presents $8.4 \mathrm{~nm}$ in thickness, implying that many MGO sheets utilized in this work are composed of $\sim 17$ stacked single-layer sheets since the average thickness of individually exfoliated GO sheet is $\sim 0.486 \mathrm{~nm}$ [20]. Selected-area electron diffraction (SED) of those stacks (Figure 1b) displays weak and diffuse rings, suggesting the loss of longrange ordering, though it is not as perfect as pristine graphene, however, blurry hexagonal symmetry of graphene was maintained. Also, parallel dark fringes are noted in the inset in Figure 1a and the spacing between neighboring fringes is $\sim 0.34 \mathrm{~nm}$, consistent with the spacing between (002) planes of graphite.

Dimensions of MGO sheets, as shown in the FESEM image (Figure 1c), are from submicron to several micrometers and a relatively large sheet is about $12 \times 20 \mu \mathrm{m}^{2}$. The sheet surface exhibits a bumpy tex-

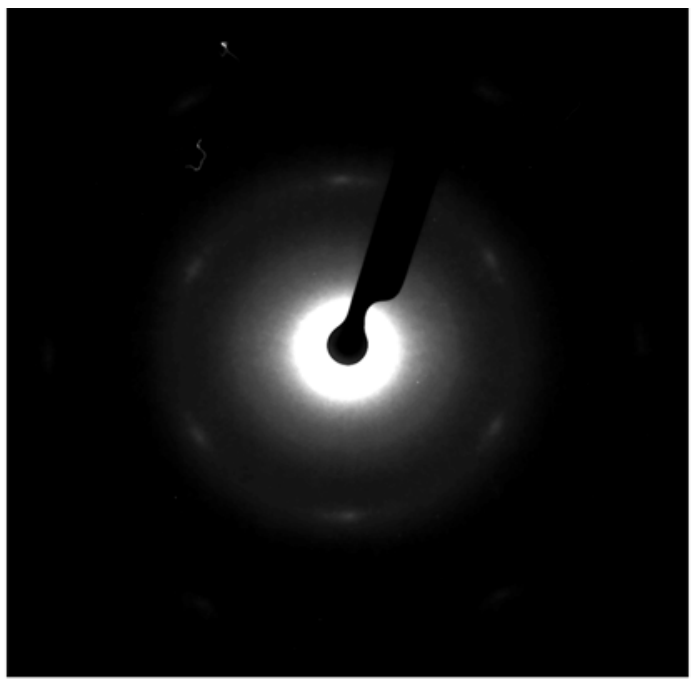

b)

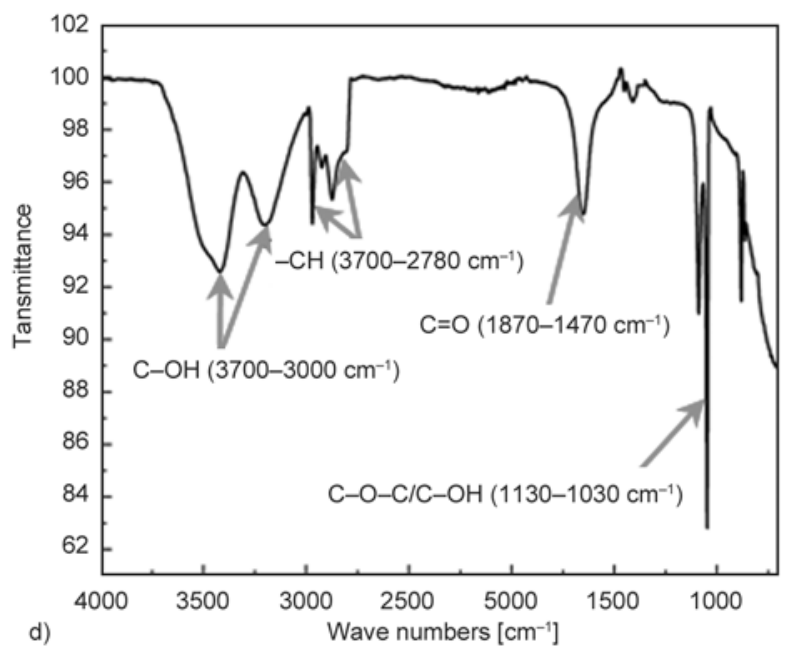

Figure 1. (a) Typical TEM image of a MGO sheet (inset: cross-section) and (b) its SED pattern; (c) FE-SEM images (inset: enlargement of the boxed region) and (d) FTIR spectrum (insets: explanatory notes for functional groups) of MGO sheets 
ture where many corrugations with several hundred nanometers are discernible (see the insert in Figure 1c). Besides the extremely small thickness, isolated oxygen reaction sites contribute to the wrinkled topology of MGO sheets at nanoscale [21] since the most characteristic feature in FTIR spectrum (Figure 1d) is the broad, intense band of $-\mathrm{OH}(3700-$ $3000 \mathrm{~cm}^{-1}$ ) as well as other bands associated with $\mathrm{C}-\mathrm{O}$ functionalities ( i.e. $\mathrm{C}=\mathrm{O}$ and $\mathrm{C}-\mathrm{O}-\mathrm{C} / \mathrm{C}-\mathrm{OH}$ ) $[11,15]$.

\subsection{Improving the thermal conductivity of epoxy by using MGO}

Firstly, strategies involving MGO content, exfoliation and dispersion state of MGO, and MGO/epoxy interfacial interaction were taken into account as follows:

As shown in Figure 2, the thermal conductivity of $\mathrm{MGO} /$ epoxy composites increases with the increasing MGO content (0.5, 1, 2 wt $\%), 2$ wt $\%$ MGO surpassed percolation threshold (falls within 1 2 $\mathrm{wt} \%$ ) and gave a maximum thermal conductivity, 2.03 times that of the epoxy. These results are comparable with the values reported in [22-25]. Further improving the thermal conductivity by increasing MGO content
(>2 wt\%) is impossible to realize since a dramatically increased viscosity had already been noticed as preparing the $2 \mathrm{wt} \% \mathrm{MGO} /$ epoxy composite with big agglomerates and trapped air bubbles impossible to be cleared in the case of higher MGO loading (see the agglomerates and through-holes emerging in the insets).

The level of exfoliation and dispersion of MGO play crucial roles in determining the ultimate performance of composites since restacking of MGO sheets significantly reduces their effectiveness for forming conductive network $[21,26]$.

$\mathrm{XRD}$ is an important tool for analyzing the exfoliation level of MGO in composites [26]. As shown in Figure 3a, WXRD pattern of graphite particles exhibits a sharp characteristic peak centered at $2 \theta=$ $26.6^{\circ}$ and a small one centered at $2 \theta=43.3^{\circ}$, which are assigned to the diffraction of (002) and (100) planes of well-ordered graphenes, respectively [27]. The as-received MGO product keeps the small one and the sharp characteristic peak disappears, which is associated with a high disorder in the direction perpendicular to MGO layers [27]. (The sharp peak at $2 \theta=26.6^{\circ}$ in graphite usually shifts to $14.1-14.9^{\circ}$ in graphite oxide, however, the peak would disappear as
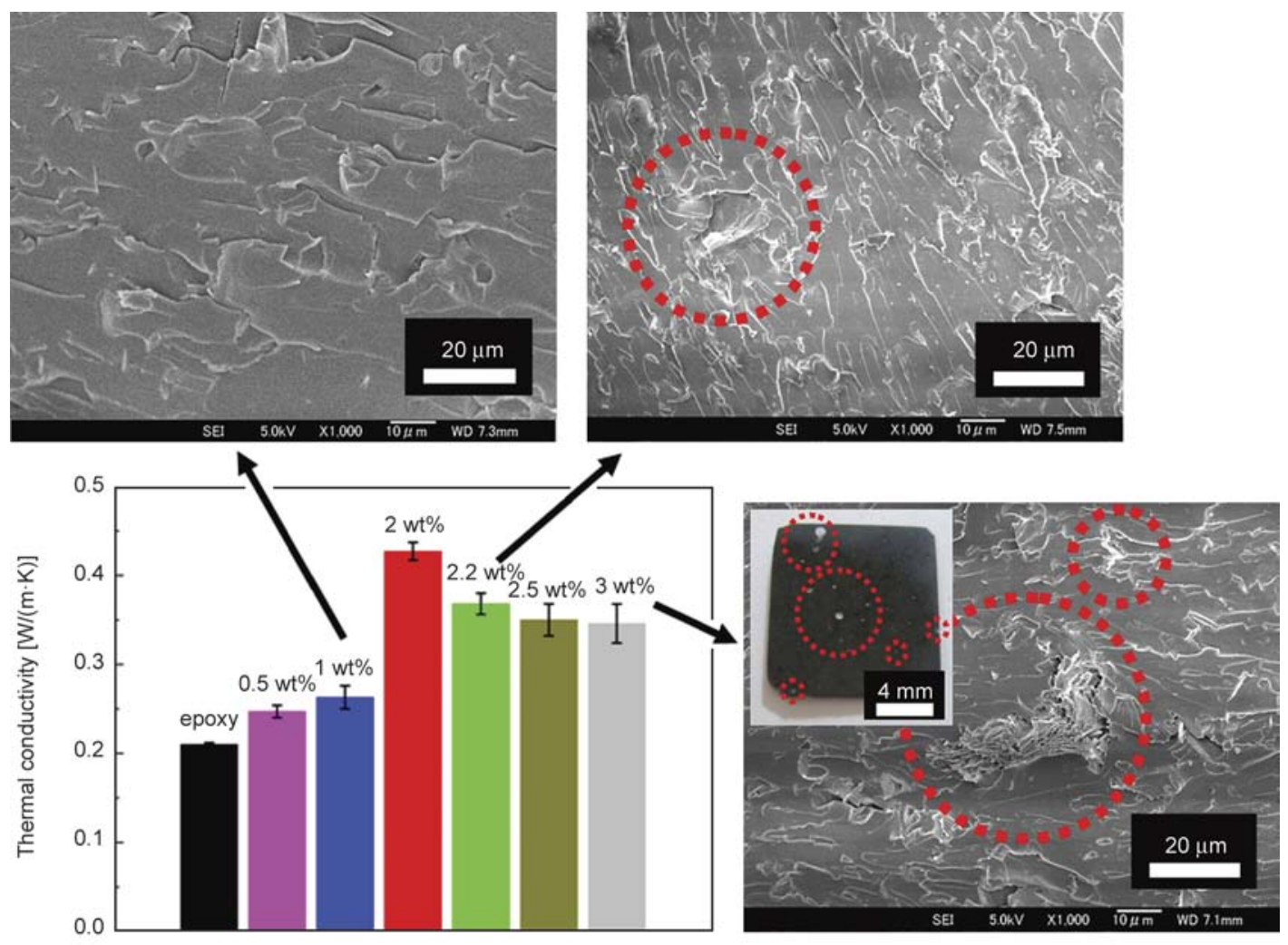

Figure 2. Thermal conductivities of MGO/epoxy composites; insets: FE-SEM images of the fracture surface of 1, 2.2, $3 \mathrm{wt} \% \mathrm{MGO} / \mathrm{epoxy}$ composites and photograph of $3 \mathrm{wt} \% \mathrm{MGO} /$ epoxy composite, circles show MGO agglomerates or through-holes 
graphite oxide exfoliates into singer sheets [18]. The small peak centered at $2 \theta=43.3^{\circ}$ usually remains in graphite oxide [27] or MGO sheets [17]). Notably, after dispersed in matrix, WXRD patterns of all the studied MGO/epoxy composites except $3 \mathrm{wt} \%$ MGO loading only show a broad diffraction peak derived form the amorphous epoxy (centered at $2 \theta=18.5^{\circ}$ ); the small peak disappears, which indicates a complete disorder in the direction perpendicular to GO layers, corresponding to an exfoliation of MGO by intercalation in epoxy matrix [18, 26-28]. Subsequently, the small diffraction peak of MGO appears (see the red circle), verifying that MGO restacks or is partially exfoliated in epoxy matrix at the $3 \mathrm{wt} \%$ loading.

The dispersion level of GO can be analyzed in the SEM observation [20,21]. As MGO loading is low,

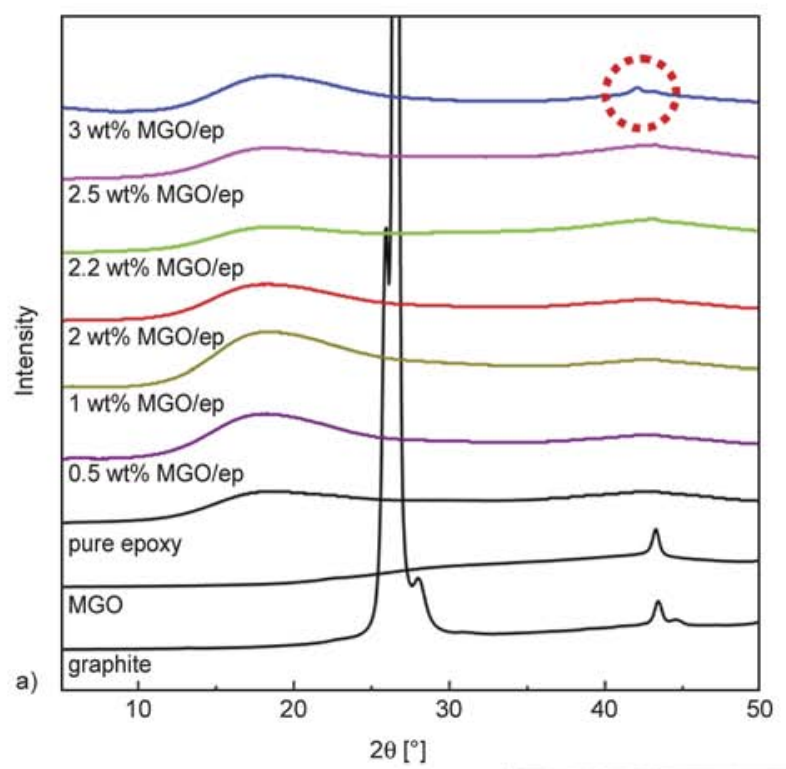

only a few scattered waves are observed on the fracture surface of $1 \mathrm{wt} \%$ MGO composite (see Figure 2). For high GO loading, in the case of poorly-dispersed $\mathrm{GO}$, the fracture surface exhibits relatively rough with some river-like structures, whereas epoxy with highly-dispersed GO presents a rougher fracture surface $[20,21]$. As compared with the FE-SEM images in Figure 2 for 2.2, $3 \mathrm{wt} \%$ MGO loadings, it can be observed that a rougher fracture surface exhibits in the FE-SEM image of Figure 3b, numerous tortuous and fine river-like structures with hackles and ribbons exist on the fracture surface, indicating that $2 \mathrm{wt} \%$ MGO were highly dispersed in the epoxy matrix (the white square in Figure $3 \mathrm{c}$ is magnified to verify the existence of individual MGO sheet). In summary, WXRD and FE-SEM results demonstrate that the mixing method utilized in this work b)

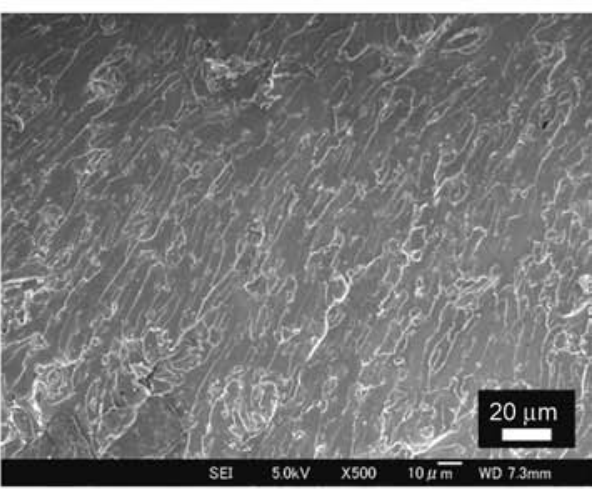

c)

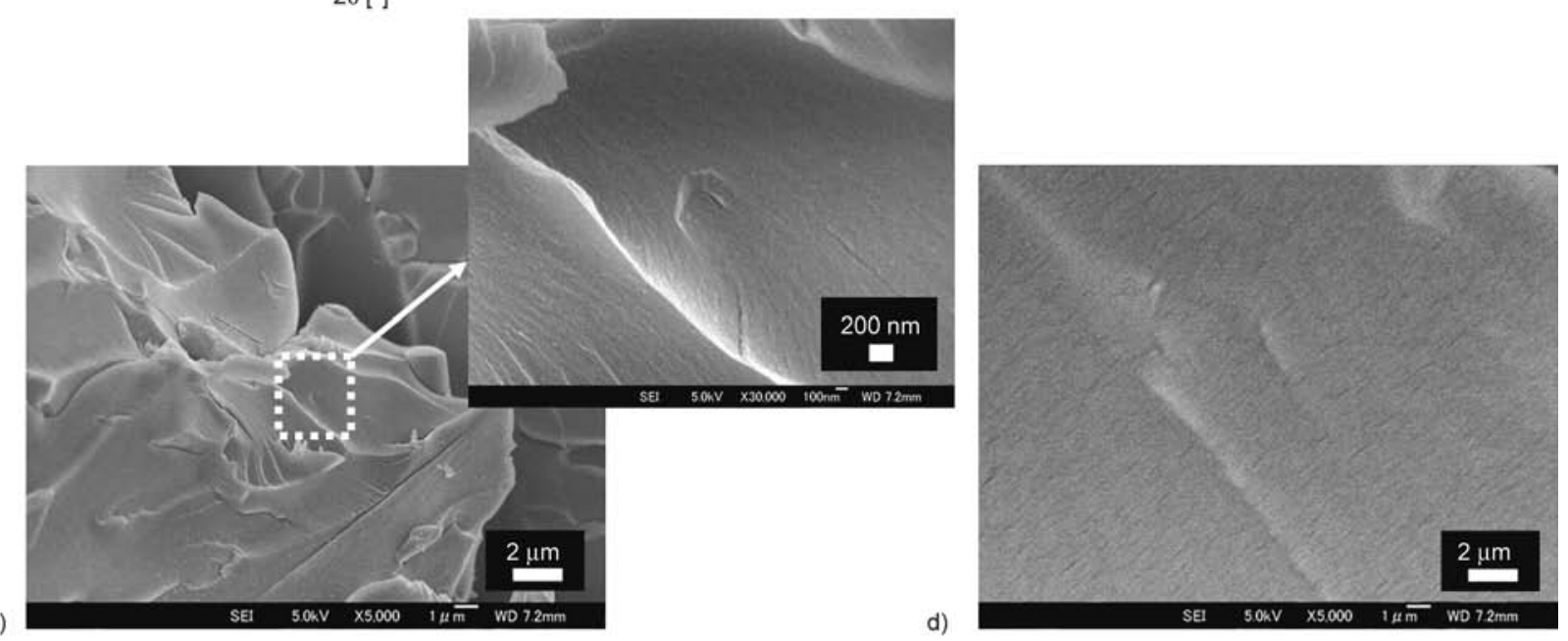

Figure 3. WXRD patterns of graphite, MGO, pure epoxy, and MGO/epoxy composites (circle shows a small peak); FESEM images of the fracture surface of $(b-c) 2 \mathrm{wt} \%$ MGO/epoxy composite (inset: enlargement of the boxed region) and (d) pure epoxy 
was effective in exfoliating and dispersing the $2 \mathrm{wt} \% \mathrm{MGO}$, and no significant restacking of MGO occurred. MGO agglomerates, through-holes, and restacking/partial exfoliation of MGO are verified to be responsible for the less enhancements in thermal conductivity with higher MGO loading ( $>2 \mathrm{wt} \%)$. It is rational to expect an ideal MGO/DGEBA interfacial interaction since the interface in $\mathrm{GO}$ /polymer composites was reported to be strengthened by grafting DGEBA molecules onto GO sheets [20, 29]. Pure epoxy is featureless as the smooth area in Figure $3 \mathrm{~d}$ with a typical brittle fracture process, improved surface roughness in Figure 3c is accompanied by a plastic deformation of epoxy matrix with an increased resistance to the deformation, demonstrating a strong bonded MGO/epoxy interface in the $2 \mathrm{wt} \%$ $\mathrm{MGO} /$ epoxy composite. Considering the negative effects of surfactants e.g. is detrimental to the inherent conductive properties of fillers [30], in this work, surface treatment of MGO using surfactants was believed unnecessary.

Overall, with these strategies $2 \mathrm{wt} \%$ MGO surpassed percolation threshold (falls within 1 2 wt\%) and achieved a maximum thermal conductivity enhancement of epoxy (2.03 times that of the epoxy). Then, one issue emerged, i.e. how to further improve the thermal conductivity of the epoxy containing MGO percolating chains.

\subsection{Exploring the formation mechanism of the $2 \mathrm{wt} \%$ MGO/epoxy percolating network based on the real-time $E(\alpha)$}

$2 \mathrm{wt} \% \mathrm{MGO} /$ epoxy percolating network dominates the properties of final product; its formation process was monitored using dynamic DSC. In dynamic DSC curve, the total area $S$ of the exothermal peak (region between the exotherm and the baseline) is in direct proportion to the specific total heat $\Delta H[\mathrm{~J} / \mathrm{g}]$ released during the reaction.

\subsubsection{Reaction mechanism of the $2 \mathrm{wt} \%$ MGO/DGEBA/6 wt\% EMI-2,4 system}

Curing mechanism of DGEBA/EMI-2,4 system (see Figure 4a) involves: (a) sequential two-step reactions (the completion of adduct reactions (I-II) is necessary prior to the etherification reaction (III)), (b) adduct products A2 act as the catalyst initiating the following etherification reaction and thus the origins of crosslinking, and (c) etherification reaction determines the final performance of cured product because epoxy molecules cross-link into the global network during this reaction stage, and it is autocatalytic since $\mathrm{A} 2$ is continually regenerated during the reaction [31].

In this study, low EMI-2,4 content, $6 \%$ by weight of DGEBA, was utilized to suppress the adduct reactions but with the generated A2 enough for initiating the etherification reaction [31], as a result, etherification reaction dominates the reaction with only one main peak appearing in each curve in Figure 5a, the heat derived from the adduct reactions (including the adduct reaction between the epoxide groups of MGO and the EMI-2,4) can be neglected, thus, $\Delta H$ can be considered as a constant over the whole reaction and the reaction rate $\mathrm{d} \alpha / \mathrm{d} t=d\left(\Delta H_{\mathrm{T}} / \Delta H\right) / \mathrm{d} t=$ $(1 / \Delta H) \mathrm{d} H / \mathrm{d} t$.

Besides, DGEBA-MGO reaction occupies an important position in the cure reaction, considering the fact that the massive $-\mathrm{OH}$ on/within $\mathrm{MGO}$ sheets also exerts catalytic effect in initiating the etherification reaction with DGEBA, establishing $\mathrm{C}-\mathrm{O}-\mathrm{C}$ bonds at the MGO/epoxy interface as depicted in Figure $4 b$, which was supported by the works on the coupling of epoxy onto GO sheets [20,29] as well as the usage of oxidized graphene as curing agent in assisting the crosslinking of epoxy [32, 33], and also was supported in this work by the evidence that $\Delta H$ value of the $2 \mathrm{wt} \% \mathrm{MGO} /$ epoxy composite exceeds that of pure epoxy standardized by the same epoxy curing degree $\alpha_{\mathrm{IR}}$ (see Table 1), i.e. $\Delta H(2 \mathrm{wt} \% \mathrm{MGO} /$ epoxy composite, $544.2 \mathrm{~J} / \mathrm{g}$ ) $>0.99 / 0.92 \Delta H$ (pure epoxy, $495.2 \mathrm{~J} / \mathrm{g}$ ).

The parabolic shape of the curves of $\mathrm{d} \alpha / \mathrm{d} t$ vs. $\alpha$ in Figure $5 \mathrm{~b}$ indicates that the addition of $2 \mathrm{wt} \%$ MGO doesn't change the autocatalytic mechanism of DGEBA/EMI-2,4 system [31].

\subsubsection{Reaction kinetics of the $2 \mathrm{wt} \%$ MGO/DGEBA/6 wt\% EMI-2,4 system}

All kinetic studies can start with the basic equation, and for thermosetting resins, $\mathrm{d} \alpha / \mathrm{d} t$ is expressed as Equation (2) [31]:

$\frac{\mathrm{d} \alpha}{\mathrm{d} t}=A \mathrm{e}^{-\mathrm{E} / \mathrm{RT}} f(\alpha)$

where $A$ is the frequency factor, $E$ is the activation energy, $R$ is the gas constant, $T$ is the absolute temperature at time $t$, and $f(\alpha)$ is a function of conver$\operatorname{sion} \alpha$. 


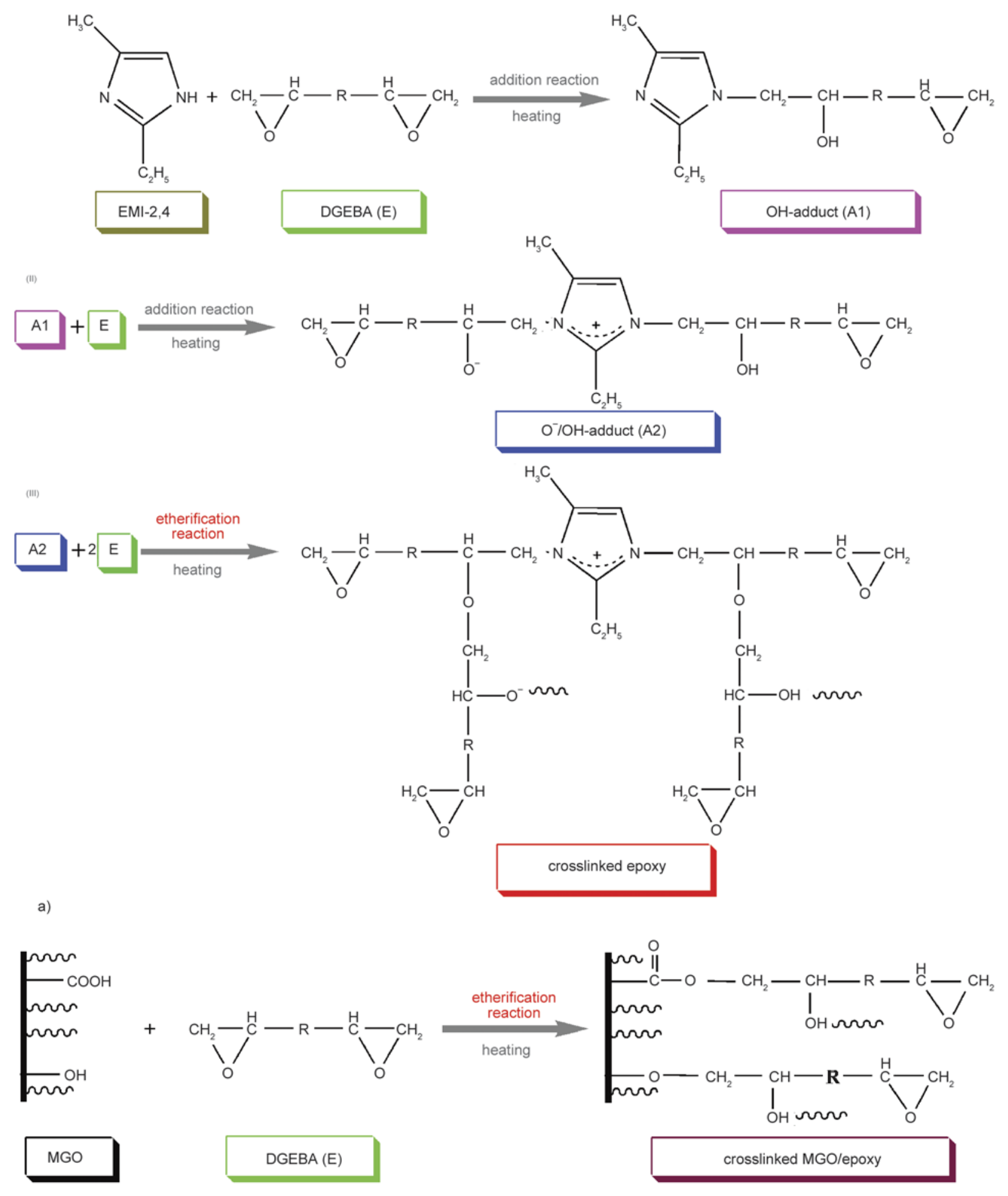

b)

Figure 4. (a) curing mechanism of DGEBA/EMI-2,4 system and (b) schematic presentation of DGEBA-MGO reactions

then: $\ln \left(\frac{\mathrm{d} \alpha}{\mathrm{d} t}\right)=\ln A-\frac{E}{R T}+\ln f(\alpha)$

let $A f(\alpha)=F(\alpha)$, then get Equation (3):

$\ln \left(\frac{\mathrm{d} \alpha}{\mathrm{d} t}\right)=-\frac{E}{R T}+\ln F(\alpha)$
Isoconversional method, by which the effect of nanosized $\mathrm{SiC}$ particles on the curing kinetics of DGEBA/ $6 \mathrm{wt} \%$ EMI-2,4 system was well established [31, 34], was also employed herein. From Equation (3), a plot of $\ln (\mathrm{d} \alpha / \mathrm{d} t)$ vs. $1 / T$ at the same $\alpha$ from a series of DSC experiments at different heating rates would result 

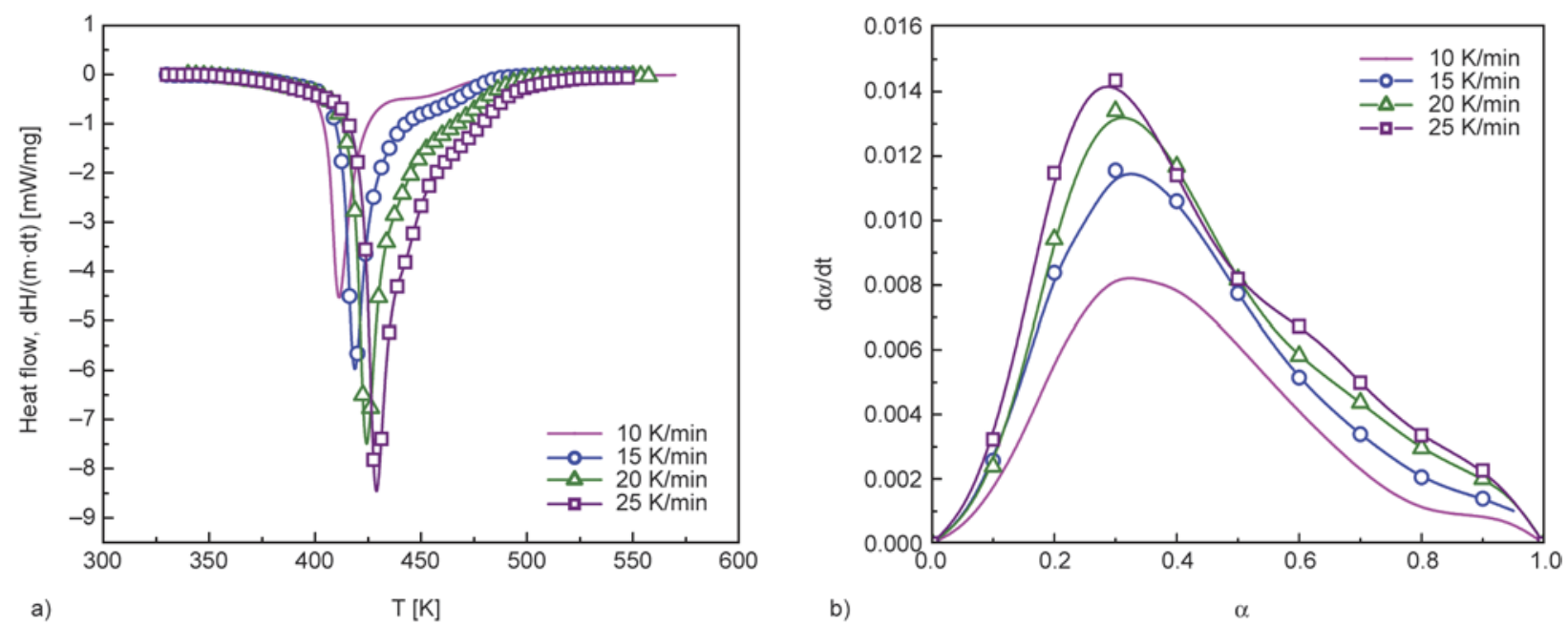

Figure 5. DSC curves (a) and plots of $\mathrm{d} \alpha / \mathrm{d} t$ vs. $\alpha$ (b) of the $2 \mathrm{wt} \% \mathrm{MGO} / \mathrm{DGEBA} / 6 \mathrm{wt} \%$ EMI-2,4 system. Curves are given only for showing the tendency.
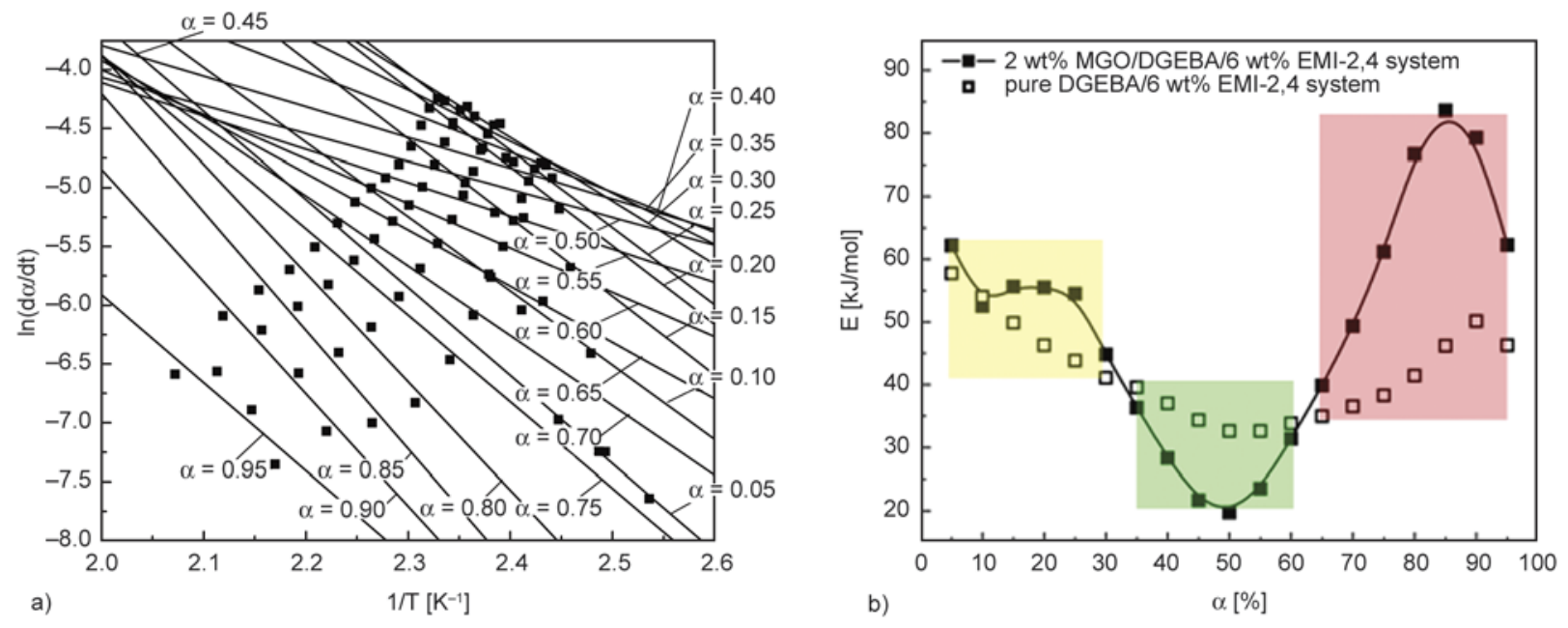

Figure 6. (a) Plots of $\ln (\mathrm{d} \alpha / \mathrm{d} t)$ vs. $1 / T$ of $2 \mathrm{wt} \% \mathrm{MGO} / \mathrm{DGEBA} / 6 \mathrm{wt} \%$ EMI-2,4 system; (b) plots of $E$ vs. $\alpha$ of $2 \mathrm{wt} \%$ MGO/DGEBA/6 wt\% EMI-2,4 system (curve is given only for showing the tendency) and DGEBA/6 wt\% EMI2,4 system (for comparison)

in a straight line with a slope of $-E / R$. Repeating this procedure, $E(\alpha)$ values corresponding to different $\alpha$ can be obtained. Figure 6a presents the plots of $\ln (\mathrm{d} \alpha / \mathrm{d} t)$ vs. $1 / T$ for various $\alpha(\alpha=0.05,0.10, \ldots$, $0.90,0.95)$, based on which the plots of $E(\alpha)$ vs. $\alpha$ were obtained (see Figure $6 \mathrm{~b}$ ). It can be seen that $E(\alpha)$ of the $2 \mathrm{wt} \%$ MGO filled system changes momentarily, spanning within $19.7 \sim 83.6 \mathrm{KJ} / \mathrm{mol}$, a broader scope than that of DGEBA/6 wt\% EMI-2,4 system $(34.3 \sim 63.8 \mathrm{KJ} / \mathrm{mol})$. The advantage of isoconversional method is that it determines $E(\alpha)$ without assuming any model and uses most of the information from curing curves, thus compared with a single $E$ averaged over the whole reaction obtained by other methods, $E(\alpha)$ has the advantage in detecting the complexity of reaction process, such as the change from chemical-kinetic control to diffusion control [34].

\subsubsection{Formation mechanism of the $2 \mathrm{wt} \%$ MGO/epoxy percolating network based on the real-time $E(\alpha)$}

A stage-dependent influence of $2 \mathrm{wt} \%$ MGO percolating chains on $E(\alpha)$ is noticed in Figure 6b. Although low content of EMI-2,4 was used to suppress adduct reactions, adduct products $\mathrm{A} 2$ are the origins of crosslinking, thus analysis on the formation process of the $2 \mathrm{wt} \% \mathrm{MGO} /$ epoxy percolating network, based on the real-time $E(\alpha)$ presented in Figure 6b, starts as follows:

(a) Adduct reactions (see Stages (i-ii) in Figure 7). Adduct reactions preferentially occur around MGO percolating chains, the preferred heatflow pathways as pre-heating temperature is applied (Stage (i)), however, each EMI-2,4 molecule only reacts with two neighboring epoxy 


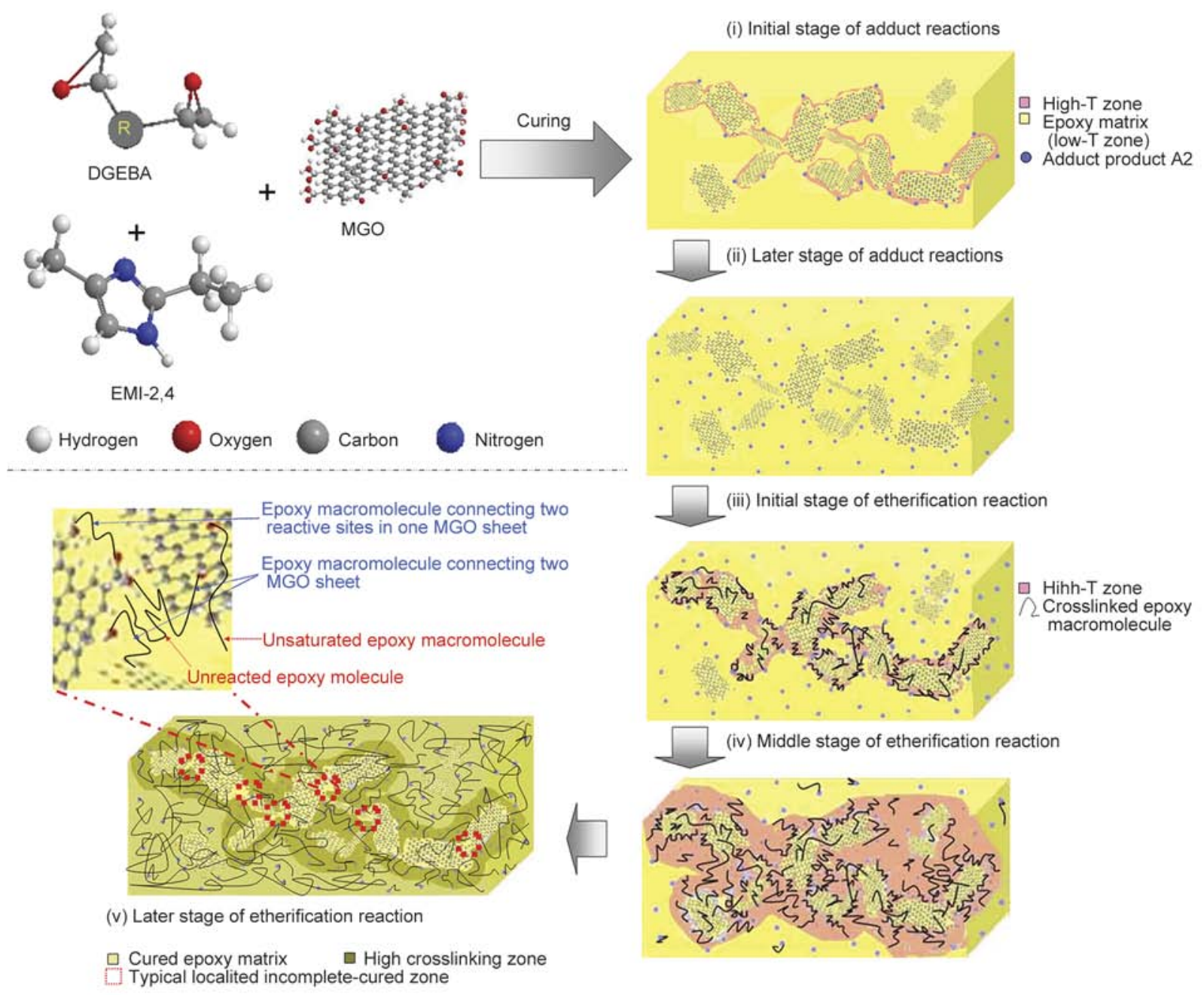

Figure 7. Schematic presentation of the crosslinking process of the MGO/epoxy percolating network

molecules before adduct reactions finish, finally, evenly distributed EMI-2,4 leads to evenly distributed resultant A2 (Stage (ii)).

(b) Etherification reaction (see Stages (iii-v) in Figure 7).

Once curing temperature is applied, etherification reaction also prefers to occur firstly around/ within the heat-flow preferred MGO percolating chains (see Stage (iii)). Initially ( $\alpha \leq 0.1)$, catalyst A2 and epoxy molecules diffuse around freely to find and react with each other; some epoxy molecules graft directly onto MGO, thus the MGO percolating chains are soon wrapped by crosslinked epoxy. Then, large amount of epoxy need skirt around these crosslinked MGO/epoxy to find and react with unreacted/unsaturated epoxy, reflected by an increased $E(0.1<\alpha \leq 0.3)$ as compared with that of counterpart stage of pure epoxy system.

Subsequently, localized networks grow into surrounding MGO-poor zone (Stage (iv)). The process is intrinsically fluent due to its autocatalytic nature [34], and particularly, driven by the temperature gradient within sample, reflected by the marked decrease in $E(0.35 \leq \alpha \leq 0.6)$ as compared with pure epoxy system and an advanced gelation (liquid-torubber transition, inflection point: pure epoxy: $\alpha=$ 0.55 ; composite: $\alpha=0.5$ ).

Significantly, at the final curing stage $(\alpha \geq 0.65)$, even if further increases the curing temperature to post-heating temperature, an unprecedentedly sharp rise in $E$ appears as compared with that of pure epoxy system, suggesting an unprecedented energy barrier hindering the residual epoxy to diffuse and react, especially those isolated within MGO-MGO interspace (see the enlargement of the boxed zones in Stage (v)) or trapped within the zone around MGO percolating chains where etherification is intensively initiated (see Stage (v)).

During the curing process, it is possible that $T_{\mathrm{g}}$ increases over heating temperature, then system vitrifies (rubber-to-glass transition) and reaction 
becomes diffusion controlled. The effect of $2 \mathrm{wt} \%$ MGO percolating chains on $T_{\mathrm{g}}$ arises from an antagonistic competition of two effects. Apart from a catalytic activity of graphitic layers on the curing of epoxy/diamine system, so far increased $T_{\mathrm{g}}$ for epoxy resins in presence of small amount of GO $(\leq 0.5 \mathrm{wt} \%$ $\mathrm{GO}[21,32])$ are mainly attributed to the reaction of epoxide with functional groups of GO [27]. In this work, the chemical bonding in MGO/epoxy interface, as well as physical hindrance of $2 \mathrm{wt} \%$ MGO percolating chains, greatly hampered epoxy motion as reflected by the sharp rise in $E$ at the final curing stage, which contributes to an increase in $T_{\mathrm{g}}$ since $T_{\mathrm{g}}$ increases with the increasing restriction imposed by crosslinking on epoxy motion [31]. On the other hand, $2 \mathrm{wt} \%$ MGO percolating chains disrupt the crosslinking of matrix [27] and the tremendous $\mathrm{MGO} /$ epoxy interface creates extra free volume assisting the epoxy motion [31], which contributes to a lowering effect on $T_{\mathrm{g}}$.

Most importantly, although the curing of pure epoxy system met with lower energy barrier as shown in Figure $6 \mathrm{~b}, \alpha_{\mathrm{IR}}$ of pure epoxy finally saturated at 0.92 , lower than that of $2 \mathrm{wt} \% \mathrm{MGO} /$ epoxy composite $(0.99$, see Table 1$)$. In fact such difference is observed only for freshly prepared samples, $\alpha_{\mathrm{IR}} \mathrm{S}$ of both pure epoxy and $2 \mathrm{wt} \% \mathrm{MGO} /$ epoxy composite approached 1.0 (the difference nearly disappears) after aging at room temperature for 6 months or thermal annealing at $523 \mathrm{~K}$ for 1 week (crosslinking can proceed as a consequence of aging or thermal annealing [27]). These results clearly suggest that the steep concentration gradient of $-\mathrm{OH}$, originated from the $2 \mathrm{wt} \%$ MGO percolating chains, exerted the vital driving force on the residual epoxy (isolated within MGO-MGO interspace or trapped within the zone around MGO percolating chains where etherification was intensively initiated) to conquer barrier for epoxy-MGO reaction, leading to the final lowering effect on $T_{\mathrm{g}}$ and higher $\alpha_{\mathrm{IR}}$ of $2 \mathrm{wt} \% \mathrm{MGO} /$ epoxy composite (see Table 1).

\subsection{Promoting intercalative crosslinking within MGO makes epoxy composite with improved thermal conductivity}

Through kinetic investigation, it is clarified that epoxy-MGO reaction plays an important role at the initial and final curing stage of epoxy containing $2 \mathrm{wt} \%$ MGO percolating chains. MGO based composites can be produced via in-situ intercalative polymerization [12]. Now, we turn our attention to the full utilization of in-situ intercalative crosslinking for the performance improvement of the composite, which need the guidance of the understanding on epoxy-MGO reaction.

Epoxy-MGO reaction can be studied based on Shrinking Core Model (SCM), the best representation for reacting fluid-particle systems [34-36]. In this work, the original sphere-shell model was modified with a cylinder-shell model customized for the special layered-structure of MGO sheet, as depicted in Figure 8.

Table 1. DSC-determined total heats of reaction $(\Delta H)$ and glass transition temperatures $\left(T_{\mathrm{g}}\right)$ at $10 \mathrm{~K} / \mathrm{min}$ heating rate; FTIRdetermined epoxy curing degree $\left(\alpha_{\mathrm{IR}}\right)$

\begin{tabular}{|c|c|c|c|}
\hline Sample & $\begin{array}{c}\Delta \mathbf{\Delta H} \\
{[\mathrm{J} / \mathrm{g}]}\end{array}$ & $\begin{array}{c}\mathbf{T}_{\mathbf{g}} \\
{[\mathbf{K}]}\end{array}$ & $\alpha_{\text {IR }}$ \\
\hline $2 \mathrm{wt} \% \mathrm{MGO} / \mathrm{DGEBA} / \mathrm{EMI}-2,4$ system & $544.2 \pm 2.9$ & $399.7 \pm 0.5$ & $0.99 \pm 0.01$ \\
\hline DGEBA/EMI-2,4 system & $495.2 \pm 1.2$ & $418.6 \pm 0.6$ & $0.92 \pm 0.01$ \\
\hline
\end{tabular}

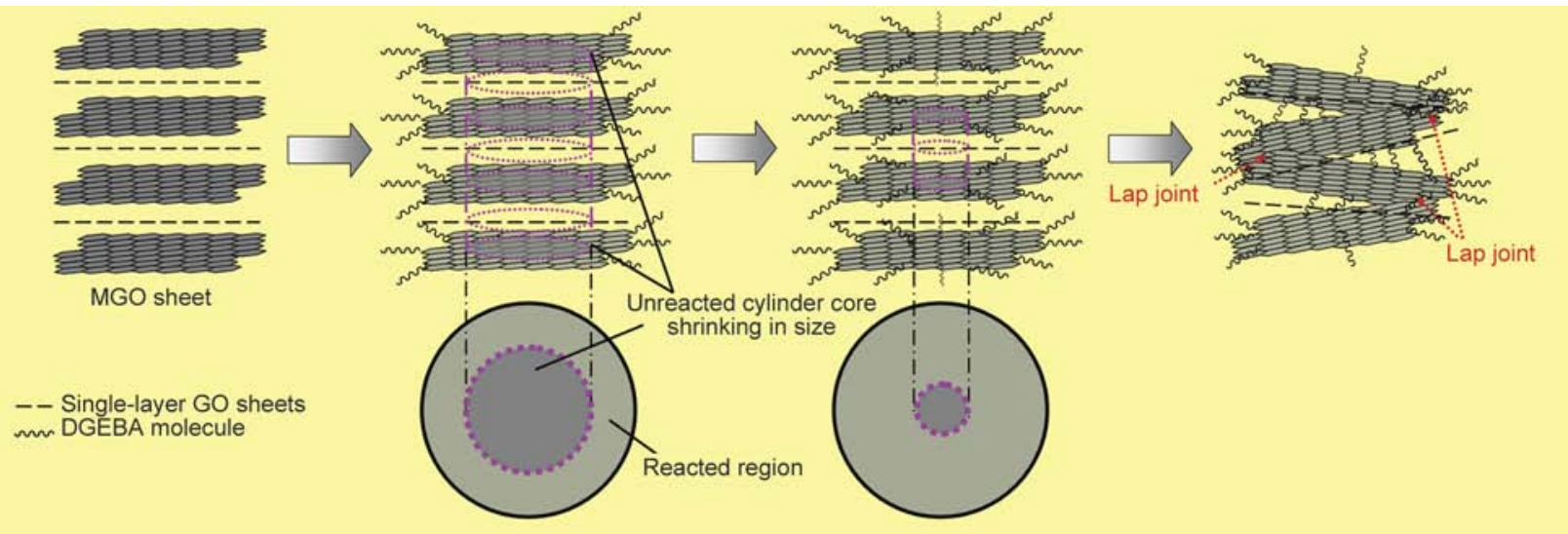

Figure 8. Schematic presentation of epoxy-MGO intercalative crosslinking by modified Shrinking Core Model 
Epoxy-MGO reaction occurs first at the outer skin of MGO sheet, and then the zone of reaction would move into inter-layer and leave behind reacted cylindrical region. Three steps occur in succession: (1) diffusion of DGEBA molecule through the liquid film surrounding the MGO chains to the surface of MGO, (2) penetration into the inter-layer spacing of MGO and diffusion of DGEBA molecule through the reacted region to the surface of unreacted cylinder core part, (3) reaction of DGEBA molecule with the unreacted cylinder core at the interface of reacted region and unreacted core region. The resistance of the different steps usually varies greatly from one and the other; in such cases we may consider that the step with the highest resistance to be rate-controlling.

In fact, the relative importance of these steps will vary as the intercalation progresses, for example, the liquid film resistance increases as the concentration of $-\mathrm{OH}$, which is the driving force for the diffusion, is decreasing as the intercalation proceeds. Therefore, the progressive intercalation crosslinking is controlled in succession by chemical reaction, reacted layer diffusion, and film diffusion. These resistances act in series, and the total resistance increases as the intercalation proceeds, which also contributes to the increase of $E$ at the final curing stage $(\alpha \geq 0.65)$. A representative schematic of resultant epoxy/MGO intercalative crosslinking structure is depicted in Figure 8 despite other possible configurations for the complexity of the reaction. Promoted intercalative crosslinking increases the probability of layerlayer lap (based on the fact that each epoxy molecule bears two terminal epoxide groups and it is inevitable that some epoxy molecules bridge neighboring layers, shorten interlayer gap, and produce more lap joints) and thus enhances the cross-plane thermal-transport ability of MGO. Therefore, promoted intercalative crosslinking is highly desirable as can open a new door for further improving the thermal conductivity of the epoxy composite containing MGO percolating chains, although it meets with higher resistance.

As proved by WXRD results, there is a complete disorder in the direction perpendicular to GO layers, corresponding to an exfoliation of $2 \mathrm{wt} \%$ MGO by intercalation in epoxy matrix. However, a lowered $T_{\mathrm{g}}$ due to the presence of $2 \mathrm{wt} \% \mathrm{MGO}$ percolating chains keeps the whole cure reaction under longterm chemical kinetic control [34], therefore, it can be inferred that the in-situ intercalative crosslinking mainly occurs at the fringe of MGO layers, and the presently utilized cure processing strategy of pure epoxy is basically adequate for the isolated/trapped epoxy molecules to conquer barriers for such intercalation at the fringe of MGO layers, but for promoting the intercalative crosslinking, systematic experiments need to be done to optimize the cure processing strategies.

Guided by the above exploration on the formation mechanism of the $2 \mathrm{wt} \% \mathrm{MGO} /$ epoxy percolating network based on real-time $E(\alpha)$ as well as the analysis of epoxy-MGO reaction based on modified SCM, targeted optimization on the cure processing strategy was accordingly proposed, which obeys the following rules: (1) at the initial stage, the curing temperature or time should be a little bit increased or prolonged, respectively, (2) at the middle stage, the curing temperature or time could be moderately decreased or shortened, respectively, (3) at the later stage, the curing temperature or time should be considerably increased or prolonged, respectively. Since the increased temperature is preferred to the prolonged time from the point of high efficiency, referring to the dynamic DSC curves in Figure 5a, a series of improved cure processing strategies was designed as tabulated in Table 2 (the curing parameters at the middle stage were fixed).

The resulting thermal conductivities presented in Figure 9 clearly shows that, increased pre-heating or post-heating temperature does bring positive effect and comparatively, pre-heating temperature has less significant effect, which can be ascribed to the fact that the deficiency in the pre-heating stage could be compensated by the following middle and/or later curing stage. Notably, S3 strategy imparts a remarkable increase in thermal conductivity (2.96 times that of epoxy), much higher than that of composite cured by the basic strategy (2.03 times that of epoxy) and similar $2 \mathrm{wt} \% \mathrm{GO} /$ epoxy composites reported [2, 37]. Further increases in thermal conductivity due to further increased curing temperatures in S4-S8 strategies is at slight degrees, specifically, to a maximum, 3.05 times that of pure epoxy (S5 strategy), indicating that thermal conductivity enhancement saturates at the S3 strategy, a strategy unprecedentedly promoting the intercalative crosslinking within MGO sheets.

Interestingly, a similar saturation phenomenon was also noticed in CTE values. As shown in Figure 10a, composite cured by the basic strategy displays a 
Table 2. Basic (cure processing strategy of pure epoxy) and improved strategies for $2 \mathrm{wt} \% \mathrm{MGO} / \mathrm{epoxy}$ composite, the curing parameters at the middle stage were fixed as $378 \mathrm{~K} \times 1.5 \mathrm{~h}$; thermal degradation data determined from TGA curves

\begin{tabular}{|l|c|c|c|c|c|}
\hline Strategies & Curing parameters & $\begin{array}{c}\mathbf{T}_{\text {onset }} \\
{[\mathbf{K}]}\end{array}$ & $\begin{array}{c}\mathbf{T}_{\text {half }} \\
{[\mathbf{K}]}\end{array}$ & $\begin{array}{c}\mathbf{T}_{\max } \\
{[\mathbf{K}]}\end{array}$ & $\begin{array}{c}\text { Char residual at 1023 K } \\
{[\%]}\end{array}$ \\
\hline Basic & $313 \mathrm{~K} \times 1 \mathrm{~h}, 458 \mathrm{~K} \times 1.5 \mathrm{~h}$ & $686.4 \pm 0.1$ & $710.8 \pm 0.2$ & $710.9 \pm 0.2$ & $13.2 \pm 0.1$ \\
\hline S1 & $333 \mathrm{~K} \times 1 \mathrm{~h}, 458 \mathrm{~K} \times 1.5 \mathrm{~h}$ & $686.4 \pm 0.1$ & $710.3 \pm 0.1$ & $710.5 \pm 0.2$ & $13.2 \pm 0.2$ \\
\hline S2 & $353 \mathrm{~K} \times 1 \mathrm{~h}, 458 \mathrm{~K} \times 1.5 \mathrm{~h}$ & $686.4 \pm 0.2$ & $710.4 \pm 0.2$ & $710.2 \pm 0.1$ & $13.2 \pm 0.1$ \\
\hline S3 & $313 \mathrm{~K} \times 1 \mathrm{~h}, 488 \mathrm{~K} \times 1.5 \mathrm{~h}$ & $693.5 \pm 0.2$ & $719.4 \pm 0.3$ & $719.3 \pm 0.2$ & $12.2 \pm 0.1$ \\
\hline S4 & $333 \mathrm{~K} \times 1 \mathrm{~h}, 488 \mathrm{~K} \times 1.5 \mathrm{~h}$ & $693.3 \pm 0.1$ & $719.9 \pm 0.2$ & $719.6 \pm 0.3$ & $12.4 \pm 0.1$ \\
\hline S5 & $353 \mathrm{~K} \times 1 \mathrm{~h}, 488 \mathrm{~K} \times 1.5 \mathrm{~h}$ & $693.2 \pm 0.2$ & $720.1 \pm 0.2$ & $719.9 \pm 0.2$ & $12.3 \pm 0.1$ \\
\hline S6 & $313 \mathrm{~K} \times 1 \mathrm{~h}, 518 \mathrm{~K} \times 1.5 \mathrm{~h}$ & $695.9 \pm 0.3$ & $721.4 \pm 0.1$ & $720.5 \pm 0.2$ & $12.3 \pm 0.1$ \\
\hline S7 & $333 \mathrm{~K} \times 1 \mathrm{~h}, 518 \mathrm{~K} \times 1.5 \mathrm{~h}$ & $695.9 \pm 0.2$ & $720.4 \pm 0.1$ & $720.8 \pm 0.3$ & $12.0 \pm 0.2$ \\
\hline S8 & $353 \mathrm{~K} \times 1 \mathrm{~h}, 518 \mathrm{~K} \times 1.5 \mathrm{~h}$ & $695.8 \pm 0.2$ & $721.9 \pm 0.2$ & $721.5 \pm 0.1$ & $12.1 \pm 0.1$ \\
\hline
\end{tabular}

$23 \%$ reduction in CTE due to the relatively rigid characteristic of MGO and the restricted epoxy motion near $\mathrm{MGO} /$ resin interface evidenced by the typical plastic deformation on the fracture surface in Figure $3 \mathrm{c}$. The obtained CTE value is comparable with

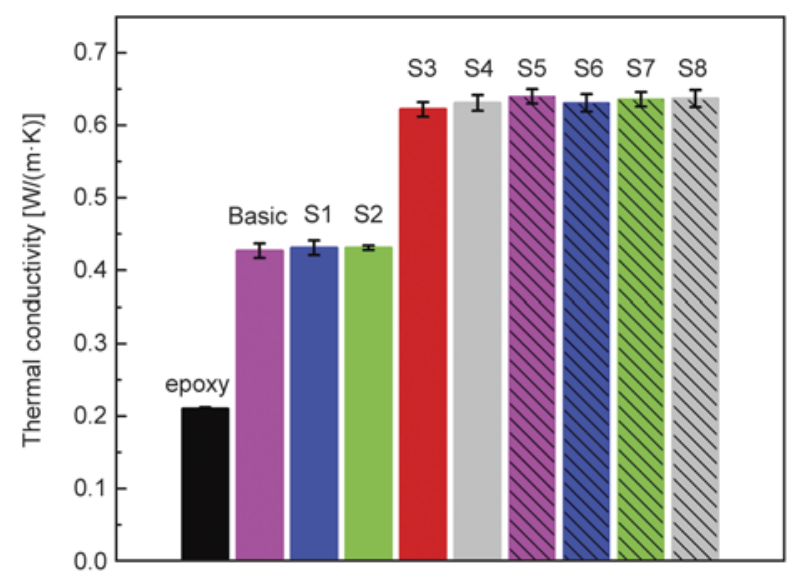

Figure 9. Thermal conductivities of $2 \mathrm{wt} \% \mathrm{MGO} / \mathrm{epoxy}$ composites obtained by the basic (cure processing strategy of pure epoxy) or improved cure processing strategies

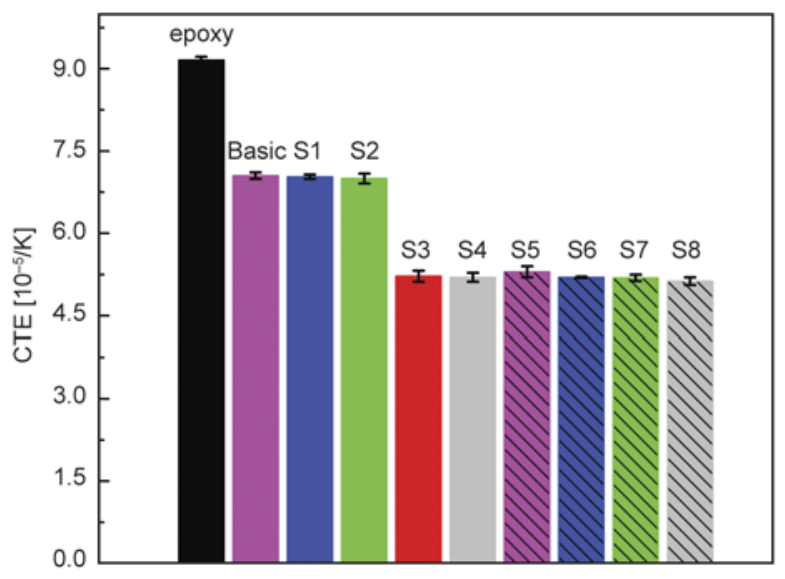

a) the reported results $[22,38]$. With S3 strategy, a further marked decrease, up to a $43 \%$ reduction in CTE, was achieved; then further decrease in CTE due to further increased curing temperature is at a slight extent, specifically from $43 \%$ to the maximum $44 \%$ reduction in CTE (S8 strategy), which confirms that S3 strategy unprecedentedly promoted the intercalative crosslinking thus making MGO sheets act at full capacity in restricting the thermal expansion behavior of epoxy by their inter-layer MGO/resin interface.

Furthermore, TGA and DTG curves (Figure 10b) exhibit a delayed thermal degradation by $2 \mathrm{wt} \%$ MGO/epoxy percolating network. For the highlyoverlapped TGA and DTG cures obtained by improved cure processing strategies, the thermal degradation onset temperature $T_{\text {onset }}$ (determined by the intersection of two tangents at the first inflection point), the half-weight-loss temperature $T_{\text {half }}$, the maximum thermal degradation temperature $T_{\max }$ (determined by the peak of DTG curve), and the char residual at $1023 \mathrm{~K}$ were summarized in Table 2 . It

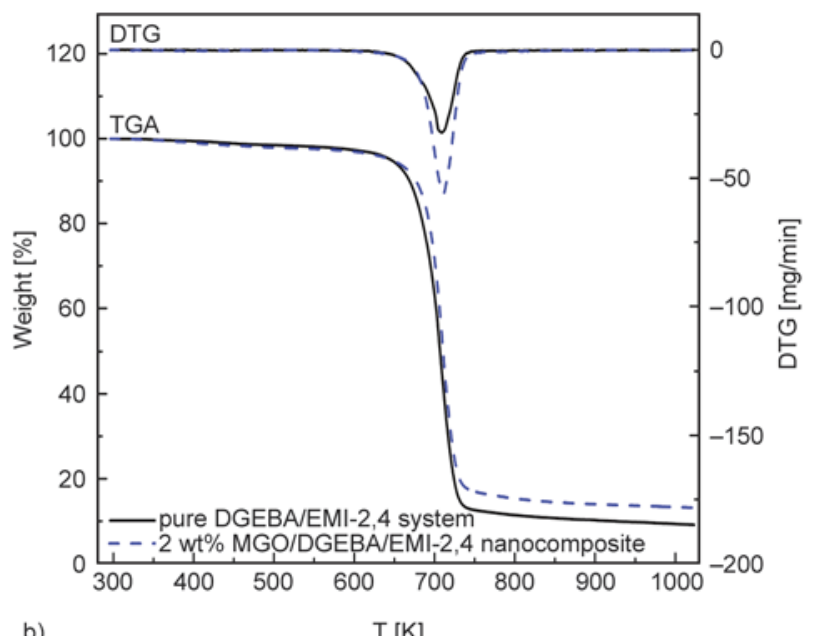

b) $\mathrm{T}[\mathrm{K}]$

Figure 10. (a) CTE values of $2 \mathrm{wt} \% \mathrm{MGO} /$ epoxy composites obtained by the basic or improved cure processing strategies, (b) TGA and DTG curves of $2 \mathrm{wt} \% \mathrm{MGO} /$ epoxy composite obtained by the basic cure processing strategy 
is a common practice to consider $T_{\text {half }}$ or $T_{\max }$ (at which weight losing rate is the maximum) as an indicator for the beginning of structural decomposition. Clearly, a significant increase in $T_{\text {onset, }}, T_{\text {half }}$ and $T_{\max }$ (specifically, 7.1, 8.6 and $8.4 \mathrm{~K}$, respectively) appears at the S3 strategy with a slight further enhancement of thermal stability in S4-S8 strategies $(2.4,2.5$ and $2.2 \mathrm{~K}$, respectively), which reconfirms an unprecedentedly promoted intercalative crosslinking by S3 strategy thus favoring the strengthening of the effectiveness of percolating network in inhibiting the thermal degradation behavior [15].

Overall, S3 strategy is considered as the optimized cure processing strategy in this work after taking both the efficiency and the performance enhancement into account.

\section{Conclusions}

In this work, strategies involving MGO content $(0.5,1,2,2.2,2.5,3 \mathrm{wt} \%)$, exfoliation and dispersion level of MGO, and MGO/epoxy interfacial interaction were firstly taken into account to improve the thermal conductivity of epoxy. With $2 \mathrm{wt} \% \mathrm{MGO}$ content, the thermal conductivity of epoxy composite reached a maximum, 2.03 times that of the epoxy. Then, one issue emerged, i.e. how to further improve the thermal conductivity of the epoxy containing $2 \mathrm{wt} \%$ MGO percolating chains.

Formation mechanism of $2 \mathrm{wt} \% \mathrm{MGO} /$ epoxy percolating network was explored, for the first time based on real-time $E(\alpha)$. The presence of $2 \mathrm{wt} \%$ MGO percolating chains leads to an unprecedentedly sharp rise in $E$ at final curing stage ( $\alpha \geq 0.65$ ), but an increased $\alpha_{\mathrm{IR}}(0.99)$ is observed as compared with that of pure epoxy (0.92). In fact such $\alpha_{\text {IR }}$ difference is observed only for freshly prepared samples, it nearly disappears after aging or thermal annealing. These results suggest that the steep concentration gradient of $-\mathrm{OH}$, originated from the $2 \mathrm{wt} \%$ MGO percolating chains, exerts the vital driving force on the residual isolated/trapped epoxy to conquer barrier for epoxy-MGO reaction.

Through kinetic investigation, it is clarified that epoxy-MGO reaction plays an important role at the initial and final curing stage. A modified Shrinking Core Model customized for the special layered-structure of MGO sheet was proposed to understand the resistance variation during the intercalative epoxy$\mathrm{MGO}$ reaction. It shows that the promoted intercala- tive crosslinking is highly desirable for further improving the thermal conductivity of the epoxy composite containing MGO percolating chains, but it meets with increased resistance.

Guided by these kinetic studies, targeted optimization on the cure processing strategy was accordingly proposed to promote the intercalative crosslinking, a thermal conductivity, 2.96 times that of the epoxy, was obtained with only a small amount $\left(30^{\circ} \mathrm{C}\right)$ increase of the post-heating temperature.

The promoted intercalative crosslinking was confirmed by CTE and TGA results. This study provides a good example of using a targeted kinetic strategy in effectively improving the thermal conductivity of the epoxy containing MGO percolating chains.

\section{Acknowledgements}

The authors are grateful for the financial support of National Natural Science Foundation of China (No. 51203074), Fundamental Research Funds for the Central Universities (No. NUST 2011YBXM163), Jiangsu Overseas Research \& Training Program for University Prominent Young \& Middleaged Teachers and Presidents, and Special Foundation for 'first-grade Zijin's Star' of 'Excellence initiative' Project of Nanjing University of Science and Technology (No. AB41339).

\section{References}

[1] Suganuma K.: Introduction to printed electronics. Springer Science, New York (2014).

DOI: $10.1007 / 978-1-4614-9625-0$

[2] Song S. H., Park K. H., Kim B. H., Choi Y. W., Jun G. H., Lee D. J., Kong B-S., Paik K-W., Jeon S.: Enhanced thermal conductivity of epoxy-graphene composites by using non-oxidized graphene flakes with non-covalent functionalization. Advanced Materials, 25, 732737 (2013).

DOI: $\underline{10.1002 / \mathrm{adma} .201202736}$

[3] Sadasivuni K. K., Ponnamma D., Thomas S., Grohens Y.: Evolution from graphite to graphene elastomer composites. Progress in Polymer Science, 39, 749-780 (2014).

DOI: $10.1016 /$ j.progpolymsci.2013.08.003

[4] Deng H., Lin L., Ji M., Zhang S., Yang M., Fu Q.: Progress on the morphological control of conductive network in conductive polymer composites and the use as electroactive multifunctional materials. Progress in Polymer Science, 39, 627-655 (2014).

DOI: 10.1016/j.progpolymsci.2013.07.007

[5] Sun X., Sun H., Li H., Peng H.: Developing polymer composite materials: Carbon nanotubes or graphene? Advanced Materials, 25, 5153-5176 (2013). DOI: $10.1002 / \mathrm{adma} .201301926$ 
[6] Wu J., Xing W., Huang G., Li H., Tang M., Wu S., Liu Y.: Vulcanization kinetics of graphene/natural rubber nanocomposites. Polymer, 54, 3314-3323 (2013).

DOI: $10.1016 /$ j.polymer.2013.04.044

[7] Wang H., Qiu Z.: Crystallization kinetics and morphology of biodegradable poly(L-lactic acid)/graphene oxide nanocomposites: Influences of graphene oxide loading and crystallization temperature. Thermochimica Acta, 527, 40-46 (2012).

DOI: $10.1016 / \mathrm{j} . t c a .2011 .10 .004$

[8] Jing X., Qiu Z.: Crystallization kinetics and thermal property of biodegradable poly(3-hydroxybutyrate)/ graphene oxide nanocomposites. Journal of Nanoscience and Nanotechnology, 12, 7314-7321 (2012). DOI: 10.1166/jnn.2012.6461

[9] Zhang F., Peng X., Yan W., Peng Z., Shen Y.: Nonisothermal crystallization kinetics of in situ nylon 6/ graphene composites by differential scanning calorimetry. Journal of Polymer Science Part B: Polymer Physics, 49, 1381-1388 (2011).

DOI: $10.1002 /$ polb. 22321

[10] Qiu S. L., Wang C. S., Wang Y. T., Liu C. G., Chen X. Y., Xie H. F., Huang Y. A., Cheng R. S.: Effects of graphene oxides on the cure behaviors of a tetrafunctional epoxy resin. Express Polymer Letters, 5, 809-818 (2011).

DOI: $10.3144 /$ expresspolymlett.2011.79

[11] Allahbakhsh A., Mazinani S., Kalaee M. R., Sharif F.: Cure kinetics and chemorheology of EPDM/graphene oxide nanocomposites. Thermochimica Acta, 563, 22 32 (2013).

DOI: $10.1016 /$ j.tca.2013.04.010

[12] Nicolosi V., Chhowalla M., Kanatzidis M. G., Strano M. S., Coleman J. N.: Liquid exfoliation of layered materials. Science, 340, 1226419/1-1226419/18 (2013). DOI: $10.1126 /$ science. 1226419

[13] Huang Y. F., Lin C. W.: Polyaniline-intercalated graphene oxide sheet and its transition to a nanotube through a self-curling process. Polymer, 53, 1079-1085 (2012).

DOI: $10.1016 /$ j.polymer.2012.01.025

[14] Bora C., Dolui S. K.: Fabrication of polypyrrole/ graphene oxide nanocomposites by liquid/liquid interfacial polymerization and evaluation of their optical, electrical and electrochemical properties. Polymer, 53, 923-932 (2012).

DOI: 10.1016/j.polymer.2011.12.054

[15] Zeng M., Wang J., Li R., Liu J., Chen W., Xu Q., Gu Y.: The curing behavior and thermal property of graphene oxide/benzoxazine nanocomposites. Polymer, 54, 3107 3116 (2013).

DOI: 10.1016/j.polymer.2013.03.069

[16] Fabbri P., Valentini L., Bon S. B., Foix D., Pasquali L., Montecchi M., Sangermano M.: In-situ graphene oxide reduction during UV-photopolymerization of graphene oxide/acrylic resins mixtures. Polymer, 53, 6039-6044 (2012).

DOI: $\underline{10.1016 / j . p o l y m e r .2012 .10 .045 ~}$
[17] Huang Y. F., Lin C. W.: Facile synthesis and morphology control of graphene oxide/polyaniline nanocomposites via in-situ polymerization process. Polymer, 53, 2574-2582 (2012).

DOI: $10.1016 /$ j.polymer.2012.04.022

[18] Kim H., Abdala A. A., Macosko C. W.: Graphene/polymer nanocomposites. Macromolecules, 43, 6515-6530 (2010).

DOI: $10.1021 / \mathrm{ma100572 \textrm {e }}$

[19] Zaman I., Phan T. T., Kuan H-C., Meng Q., Bao La L. T., Luong L., Youssf O., Ma J.: Epoxy/graphene platelets nanocomposites with two levels of interface strength. Polymer, 52, 1603-1611 (2011).

DOI: $10.1016 /$ j.polymer.2011.02.003

[20] Wan Y-J., Tang L-C., Gong L-X., Yan D., Li Y-B., Wu LB., Jiang J-X., Lai G-Q.: Grafting of epoxy chains onto graphene oxide for epoxy composites with improved mechanical and thermal properties. Carbon, 69, 467480 (2014).

DOI: $10.1016 /$ j.carbon.2013.12.050

[21] Tang L-C., Wan Y-J., Yan D., Pei Y-B., Zhao L., Li YB., Wu L-B., Jiang J-X., Lai G-Q.: The effect of graphene dispersion on the mechanical properties of graphene/epoxy composites. Carbon, 60, 16-27 (2013). DOI: 10.1016/j.carbon.2013.03.050

[22] Ahmadi-Moghadam B., Taheri F.: Effect of processing parameters on the structure and multi-functional performance of epoxy/GNP-nanocomposites. Journal of Materials Science, 49, 6180-6190 (2014).

DOI: $10.1007 / \mathrm{s} 10853-014-8332-y$

[23] Wang F., Drzal L. T., Qin Y., Huang Z.: Mechanical properties and thermal conductivity of graphene nanoplatelet/epoxy composites. Journal of Materials Science, 50, 1082-1093 (2015).

DOI: $10.1007 / \mathrm{s} 10853-014-8665-6$

[24] Zhang K., Zhang Y., Wang S.: Effectively decoupling electrical and thermal conductivity of polymer composites. Carbon, 65, 105-111 (2013). DOI: $10.1016 /$ j.carbon.2013.08.005

[25] Zhang K., Zhang Y., Wang S.: Enhancing thermoelectric properties of organic composites through hierarchical nanostructures. Scientific Reports, 3, 3448/13448/7 (2013).

DOI: $10.1038 /$ srep03448

[26] Guan L-Z., Wan Y-J., Gong L-X., Yan D., Tang L-C., Wu L-B., Jiang J-X., Lai G-Q.: Toward effective and tunable interphases in graphene oxide/epoxy composites by grafting different chain lengths of polyetheramine onto graphene oxide. Journal of Materials Chemistry A, 2, 15058-15069 (2014). DOI: $10.1039 / \mathrm{C} 4 \mathrm{TA} 02429 \mathrm{~J}$

[27] Mauro M., Acocella M. R., Corcione C. E., Maffezzoli A., Guerra G.: Catalytic activity of graphite-based nanofillers on cure reaction of epoxy resins. Polymer, 55, 5612-5615 (2014).

DOI: $10.1016 /$ j.polymer.2014.09.019 
[28] Wan Y-J., Gong L-X., Tang L-C., Wu L-B., Jiang J-X.: Mechanical properties of epoxy composites filled with silane-functionalized graphene oxide. Composites Part A: Applied Science and Manufacturing, 64, 79-89 (2014).

DOI: 10.1016/j.compositesa.2014.04.023

[29] Shen B., Zhai W., Tao M., Lu D., Zheng W.: Chemical functionalization of graphene oxide toward the tailoring of the interface in polymer composites. Composites Science and Technology, 77, 87-94 (2013). DOI: 10.1016/j.compscitech.2013.01.014

[30] Krishnan D., Kim F., Luo J., Cruz-Silva R., Cote L. J., Jang H. D., Huang J.: Energetic graphene oxide: Challenges and opportunities. Nano Today, 7, 137-152 (2012). DOI: $10.1016 / \mathrm{j}$.nantod.2012.02.003

[31] Zhou T., Gu M., Jin Y., Wang J.: Studying on the curing kinetics of a DGEBA/EMI-2,4/nano-sized carborundum system with two curing kinetic methods. Polymer, 46, 6174-6181 (2005).

DOI: $10.1016 /$ j.polymer.2005.03.114

[32] Shen X-J., Pei X-Q., Fu S-Y., Friedrich K.: Significantly modified tribological performance of epoxy nanocomposites at very low graphene oxide content. Polymer, 54, 1234-1242 (2013).

DOI: 10.1016/j.polymer.2012.12.064

[33] Patil V., Dennis R. V., Rout T. K., Banerjee S., Yadav G. D.: Graphene oxide and functionalized multi walled carbon nanotubes as epoxy curing agents: A novel synthetic approach to nanocomposites containing active nanostructured fillers. RSC Advances, 4, 49264-49272 (2014). DOI: $10.1039 / \mathrm{c} 4 \mathrm{ra} 09693 \mathrm{~b}$
[34] Zhou T., Gu M., Jin Y., Wang J.: Isoconversional method to explore the cure reaction mechanisms and curing kinetics of DGEBA/EMI-2,4/nano-SiC system. Journal of Polymer Science Part A: Polymer Chemistry, 44, 371-379 (2006).

DOI: $10.1002 /$ pola.21150

[35] Knorr T., Kaiser M., Glenk F., Etzold B. J. M.: Shrinking core like fluid solid reactions - A dispersion model accounting for fluid phase volume change and solid phase particle size distributions. Chemical Engineering Science, 69, 492-502 (2012).

DOI: $10.1016 /$ j.ces.2011.11.002

[36] Shi B-H., Fan S-S., Lou X.: Application of the shrinking-core model to the kinetics of repeated formation of methane hydrates in a system of mixed dry-water and porous hydrogel particulates. Chemical Engineering Science, 109, 315-325 (2014).

DOI: $10.1016 /$ j.ces.2014.01.035

[37] Kim J., Yim B-S., Kim J-M., Kim J.: The effects of functionalized graphene nanosheets on the thermal and mechanical properties of epoxy composites for anisotropic conductive adhesives (ACAs). Microelectronics Reliability, 52, 595-602 (2012).

DOI: $10.1016 /$ j.microrel.2011.11.002

[38] Wang S., Tambraparni M., Qiu J., Tipton J., Dean D.: Thermal expansion of graphene composites. Macromolecules, 42, 5251-5255 (2009). DOI: $10.1021 / \mathrm{ma900631 \textrm {c }}$ 